\title{
Evolution of the graded repair of CSF leaks and skull base defects in endonasal endoscopic tumor surgery: trends in repair failure and meningitis rates in 509 patients
}

\author{
*Andrew Conger, MD, ${ }^{1}$ Fan Zhao, MD, PhD, ${ }^{2}$ Xiaowen Wang, MD, ${ }^{2}$ Amalia Eisenberg, NP, ${ }^{3}$ \\ Chester Griffiths, MD, ${ }^{3}$ Felice Esposito, MD, PhD, ${ }^{4}$ Ricardo L. Carrau, MD, ${ }^{5}$ \\ Garni Barkhoudarian, MD, ${ }^{3}$ and Daniel F. Kelly, MD $^{3}$
}

1Department of Neurosurgery, Geisinger Health System, Danville, Pennsylvania; 'Department of Neurosurgery, Fudan University, Shanghai, China; ${ }^{3}$ Pacific Pituitary Disorders Center, John Wayne Cancer Institute, Providence Saint John's Health Center, Santa Monica, California; ${ }^{4}$ Department of Biomedical and Dental Sciences and Morpho-Functional Imaging, Division of NeuroSurgery, Università degli Studi di Messina, Messina, Italy; and ${ }^{5}$ Department of Otolaryngology-Head \& Neck Surgery, The Ohio State University Medical Center, Columbus, Ohio

\begin{abstract}
OBJECTIVE The authors previously described a graded approach to skull base repair following endonasal microscopic or endoscope-assisted tumor surgery. In this paper they review their experience with skull base reconstruction in the endoscopic era.
\end{abstract}

METHODS A retrospective review of a single-institution endonasal endoscopic patient database (April 2010-April 2017) was undertaken. Intraoperative CSF leaks were graded based on size (grade 0 [no leak], 1, 2, or 3), and repair technique was documented across grades. The series was divided into 2 epochs based on implementation of a strict perioperative antibiotic protocol and more liberal use of permanent and/or temporary buttresses; repair failure rates and postoperative meningitis rates were assessed for the 2 epochs and compared.

RESULTS In total, 551 operations were performed in 509 patients for parasellar pathology, including pituitary adenoma $(66 \%)$, Rathke's cleft cyst $(7 \%)$, meningioma $(6 \%)$, craniopharyngioma $(4 \%)$, and other $(17 \%)$. Extended approaches were used in $41 \%$ of cases. There were 9 postoperative CSF leaks (1.6\%) and 6 cases of meningitis (1.1\%). Postoperative leak rates for all 551 operations by grade $0,1,2$, and 3 were $0 \%, 1.9 \%, 3.1 \%$, and $4.8 \%$, respectively. Fat grafts were used in $33 \%, 84 \%, 97 \%$, and $100 \%$ of grade $0,1,2$, and 3 leaks, respectively. Pedicled mucosal flaps (78 total) were used in $2.6 \%$ of grade $0-2$ leaks (combined) and $79.5 \%$ of grade 3 leaks (60 nasoseptal and 6 middle turbinate flaps). Nasoseptal flap usage was highest for craniopharyngioma operations (80\%) and lowest for pituitary adenoma operations (2\%). Two (3\%) nasoseptal flaps failed. Contributing factors for the 9 repair failures were $\mathrm{BMI} \geq 30$ (7/9), lack of buttress (4/9), grade 3 leak (4/9), and postoperative vomiting (4/9). Comparison of the epochs showed that grade 1-3 repair failures decreased from $6 / 143(4.1 \%)$ to $3 / 141(2.1 \%)$ and grade $1-3$ meningitis rates decreased from $5(3.5 \%)$ to $1(0.7 \%)(p=0.08)$. Prophylactic lumbar CSF drainage was used in only 4 cases $(<1 \%)$, was associated with a higher meningitis rate in grades $1-3(25 \%$ vs $2 \%$ ), and was discontinued in 2012. Comparison of the 2 epochs showed increase buttress use in the second, with use of a permanent buttress in grade 1 and 3 leaks increasing from $13 \%$ to $55 \%$ and $32 \%$ to $76 \%$, respectively $(p<0.001)$, and use of autologous septal/keel bone as a permanent buttress in grade 1, 2, and 3 leaks increasing from $15 \%$ to $51 \%(p<0.001)$. CONCLUSIONS A graded approach to skull base repair after endonasal surgery remains valid in the endoscopic era. However, the technique has evolved significantly, with further reduction of postoperative CSF leak rates. These data suggest that buttresses are beneficial for repair of most grade 1 and 2 leaks and all grade 3 leaks. Similarly, pedicled flaps appear advantageous for grade 3 leaks, while CSF diversion may be unnecessary and a risk factor for meningitis. High BMI should prompt an aggressive multilayered repair strategy. Achieving repair failure and meningitis rates lower than $1 \%$ is a reasonable goal in endoscopic skull base tumor surgery.

https://thejns.org/doi/abs/10.3171/2017.11.JNS172141

KEYWORDS cerebrospinal fluid leak; endonasal surgery; endoscopic surgery; skull base tumor; pituitary adenoma; chordoma; craniopharyngioma; meningioma; meningitis; lumbar drain; pituitary surgery

ABBREVIATIONS CNS = Congress of Neurological Surgeons; $P O D=$ postoperative day. SUBMITTED August 27, 2017. ACCEPTED November 28, 2017. INCLUDE WHEN CITING Published online May 11, 2018; DOI: 10.3171/2017.11.JNS172141.

* A.C. and F.Z. share first authorship of this work. 
$\mathrm{O}$ VER the last decade, the endonasal endoscopic approach has gradually become the predominant method for removal of pituitary adenomas and related parasellar tumors in many countries around the world. , $, 6,19,32,35$ After tumor removal, an effective exit strategy is essential to avoid a postoperative CSF leak and its related complications-meningitis, pneumocephalus, and reoperation..$^{2,8,10,11}$ In 2007, we published a CSF leak grading system and repair protocol validated in a series of over 600 patients treated by an endonasal microscopic approach. ${ }^{9}$ That report stressed a graded approach to skull base repair based on the size of the leak (grade $0,1,2$, or 3 ) and the need for a soft or rigid buttress construct to minimize the effects of CSF pulsations and brain edema and eliminate the risk of repair failure. This current report updates our use of a graded approach to skull base repair and CSF leak prevention following the adoption of endoscopic techniques and the advent of the pedicled nasoseptal flap ${ }^{14,20}$ in a series of over 500 consecutive patients. An assessment of the evolution of the technique and materials used and analysis of repair failures and postoperative meningitis are provided. The essential premise of the original paper has remained, namely that 1) smaller leaks can generally be repaired in a more minimalist fashion while larger defects require maximal and multiple measures, and 2) the majority of CSF leak repairs warrant a rigid permanent buttress placed within the sphenoid sinus/sellar region or at least a temporary soft buttress to hold the repair in position.

\section{Methods \\ Patient Population}

Following approval of the study protocol by Western Institutional Review Board, the prospectively collected patient database at Pacific Neuroscience Institute at Providence Saint John's Health Center (Santa Monica, California) was retrospectively reviewed, identifying those patients who underwent fully endonasal endoscopic tumor or cyst removal performed by a neurosurgical and otolaryngology team from April 2010 to April 2017. Patients operated on by a microscopic transsphenoidal approach with endoscopic assistance, the last of which was performed in 2011, were not included. Operative notes and follow-up clinic notes of all included patients were reviewed for demographic data, BMI, tumor pathology, CSF leak grade and repair method, and complications. All procedures were performed by the senior author (D.F.K.) or by G.B. with otolaryngology/ENT collaboration by C.G., R.L.C., and Dr. Kian Karimi. All patients had at least 3 months' postoperative follow-up.

\section{Assessment for an Intraoperative CSF Leak}

As previously described, patients were operated on via a fully endonasal endoscopic approach using a binostril 2-surgeon approach. ${ }^{13,21,27}$ In patients without the anticipated need for a nasoseptal flap, a bilateral rescue flap technique with preservation of the sphenopalatine artery and septal olfactory strip was performed..$^{13}$ After tumor or cyst removal, and obtaining hemostasis, a determination was made as to whether a CSF leak was present, its location (if one was present), and grade $(0,1,2$, or 3$) .{ }^{9}$ To identify small leaks, a Valsalva maneuver was applied by the anesthesiologist to an intrathoracic pressure of approximately $30-40 \mathrm{~mm} \mathrm{Hg}$ to transiently elevate intracranial pressure and provoke CSF egress while the intrasellar space was observed.

\section{CSF Leak Grading System and Repair Protocol}

As previously described, intraoperative CSF leaks were assessed and categorized by the neurosurgical team at surgery (and recorded in the operative dictation) based on grade: grade 0 , no leak observed; grade 1, small "weeping" CSF leak confirmed by Valsalva maneuver without a visible diaphragmatic defect; grade 2 , moderate leak with definite diaphragmatic defect; or grade 3, large diaphragmatic and/or dural defect created as part of a suprasellar, planum, or transclival extended transsphenoidal approach (Table 1). ${ }^{9}$

The steps and materials used currently for skull base repair, based on CSF leak grade, are described below (Table 1, Figs. 1 and 2, and Video 1).

VIDEO 1. Excerpts of 4 operations depicting closure techniques for grade 0,1,2, and 3 CSF leaks with narration. Copyright Pacific Neuroscience Institute. Published with permission. Click here to view.

\section{Grade 0 (no leak)}

The sellar resection cavity is covered or filled with a single layer of collagen sponge (Helistat absorbable collagen hemostatic sponge, Integra LifeSciences Corp.), the anterior sellar dura is returned to its anatomical position, and a second layer of collagen sponge is layered over the sella and adjacent sphenoid bone. If adjacent sellar mucosa is available, it is layered back over the sella and collagen, followed by a small amount of tissue glue (Tisseel fibrin sealant, Baxter International Inc.). There are several exceptions to this simple repair for grade 0 cases. For pituitary adenoma and Rathke's cleft cyst cases with a large sellar dead space and/or a very thinned diaphragma, an intrasellar abdominal fat graft is placed to obliterate the dead space, instead of intrasellar collagen (33\% in this series). In a small minority of cases (4\% in this series), including those involving patients with BMI $>30$ and a thinned diaphragma sellae, a harvested bony buttress or synthetic buttress (Medpor TSI, Stryker Corporation) may be wedged into the intrasellar extradural space. If a solid buttress is not available or cannot be wedged, then a temporary sponge buttress (foam polymer of polyvinyl alcohol, Merocel, Medtronic Inc.) can be placed under direct visualization for 5 days. For patients with invasive parasellar meningiomas or chordomas, particularly those with exposed paraclival and cavernous carotid arteries, and a likelihood of needing radiotherapy, a nasoseptal or middle turbinate flap is placed over the carotid arteries and resection area, followed by collagen sponge.

\section{Grade 1 (weeping CSF leak)}

The sellar resection cavity is typically filled with an abdominal fat graft to obliterate any dead space (performed in $83.5 \%$ of cases of grade 1 leak in this series). The anterior sellar dura is returned to its anatomical position 
TABLE 1. Operative steps of CSF repair by leak grade-current repair protocol

\begin{tabular}{|c|c|c|}
\hline Leak Grade & Description of CSF Leak & Steps of Repair \\
\hline Grade 0 & $\begin{array}{l}\text { Absence of CSF leak, confirmed by } \\
\text { Valsalva maneuver }\end{array}$ & $\begin{array}{l}\text { 1) Intrasellar fat graft if large sellar dead space } \\
\text { 2) Collagen sponge on-lay over gland, diaphragma, parasellar bone } \\
\text { 3) Repositioning of sphenoid sinus mucosa over sella \& collagen } \\
\text { 4) Collagen sponge over mucosa \& posterior sphenoid then tissue glue }\end{array}$ \\
\hline Grade 1 & $\begin{array}{l}\text { Small "weeping" leak, confirmed } \\
\text { by Valsalva maneuver, w/ small } \\
\text { diaphragmatic defect }\end{array}$ & $\begin{array}{l}\text { 1) Intrasellar fat graft if large sellar dead space } \\
\text { 2) Collagen sponge on-lay over gland, diaphragma, parasellar bone } \\
\text { 3) Bone or synthetic buttress (intrasellar, extradural) if safe } \\
\text { 4) Repositioning of sphenoid sinus mucosa over sellar defect \& buttress } \\
\text { 5) Second layer of collagen sponge over defect then tissue glue } \\
\text { 6) If unable to wedge rigid buttress, then uni- or binostril Merocel tampon }\end{array}$ \\
\hline Grade 2 & $\begin{array}{l}\text { Moderate CSF leak, w/ obvious } \\
\text { diaphragmatic defect }\end{array}$ & $\begin{array}{l}\text { 1) Intrasellar fat graft } \\
\text { 2) Collagen sponge on-lay over gland, diaphragma, parasellar bone } \\
\text { 3) Bone or synthetic buttress (intrasellar, extradural) if safe } \\
\text { 4) Repositioning of sphenoid sinus mucosa over sellar defect \& buttress } \\
\text { 5) Additional fat in sphenoid sinus } \\
\text { 6) Second layer collagen sponge over fat graft then tissue glue } \\
\text { 7) If unable to wedge rigid buttress, then uni- or binostril Merocel tampons }\end{array}$ \\
\hline Grade 3 & $\begin{array}{l}\text { Large CSF leak, as part of extended } \\
\text { transsphenoidal approach (typically } \\
\text { transplanum or transclival) }\end{array}$ & $\begin{array}{l}\text { 1) Intrasellar, suprasellar, \&/or clival fat graft } \\
\text { 2) Collagen sponge on-lay over gland, fat graft, \& bony defect edges } \\
\text { 3) Bone or synthetic buttress wedged or fitted w/in bony defect } \\
\text { 4) Nasoseptal pedicled flap layered over defect } \\
\text { 5) Additional fat over flap } \\
\text { 6) Second layer collagen sponge over fat then tissue glue } \\
\text { 7) Binostril Merocel tampons to help oppose nasoseptal flap to skull base }\end{array}$ \\
\hline
\end{tabular}

and collagen sponge is layered over the sella and adjacent sphenoid. In a large minority of cases (34\% in this series), particularly patients with BMI $>30$ and/or a large area of thinned diaphragma sellae, a buttress of septal bone or, less frequently, a synthetic buttress (e.g., Medpor TSI) is wedged into the intrasellar extradural space, typically from side to side (Fig. 3). If adjacent mucosa is available, it is layered back over the sella and collagen, followed by a tissue glue (Tisseel fibrin sealant) layered over the collagen and/or mucosa. If a solid buttress is not available or cannot be wedged due to the large defect with exposed cavernous carotids, then single or bilateral Merocel sponges are placed as a temporary buttress for 5 days.

\section{Grade 2 (moderate CSF leak)}

The sellar resection cavity is filled with abdominal fat

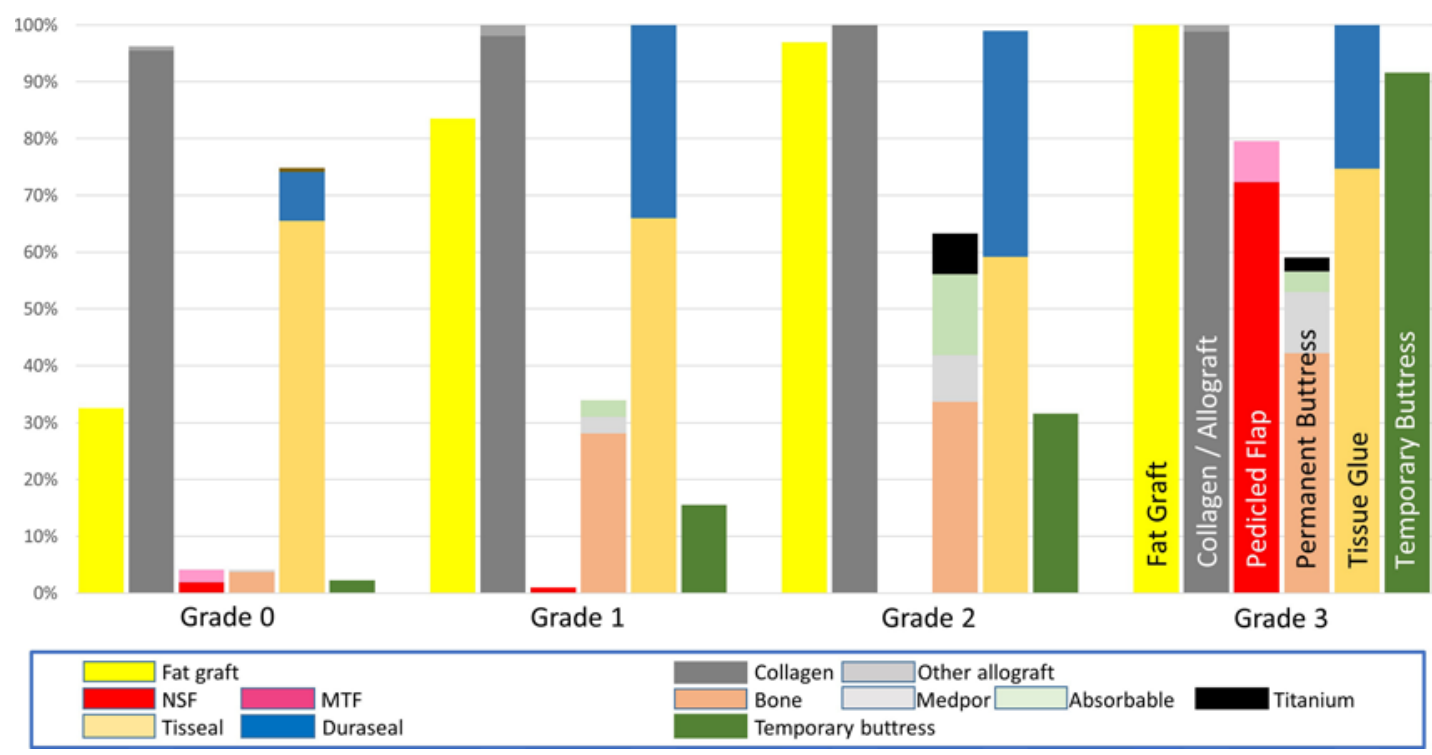

FIG. 1. Reconstruction materials used by CSF leak grade in 551 operations. MTF = middle turbinate flap; NSF = nasoseptal flap. 

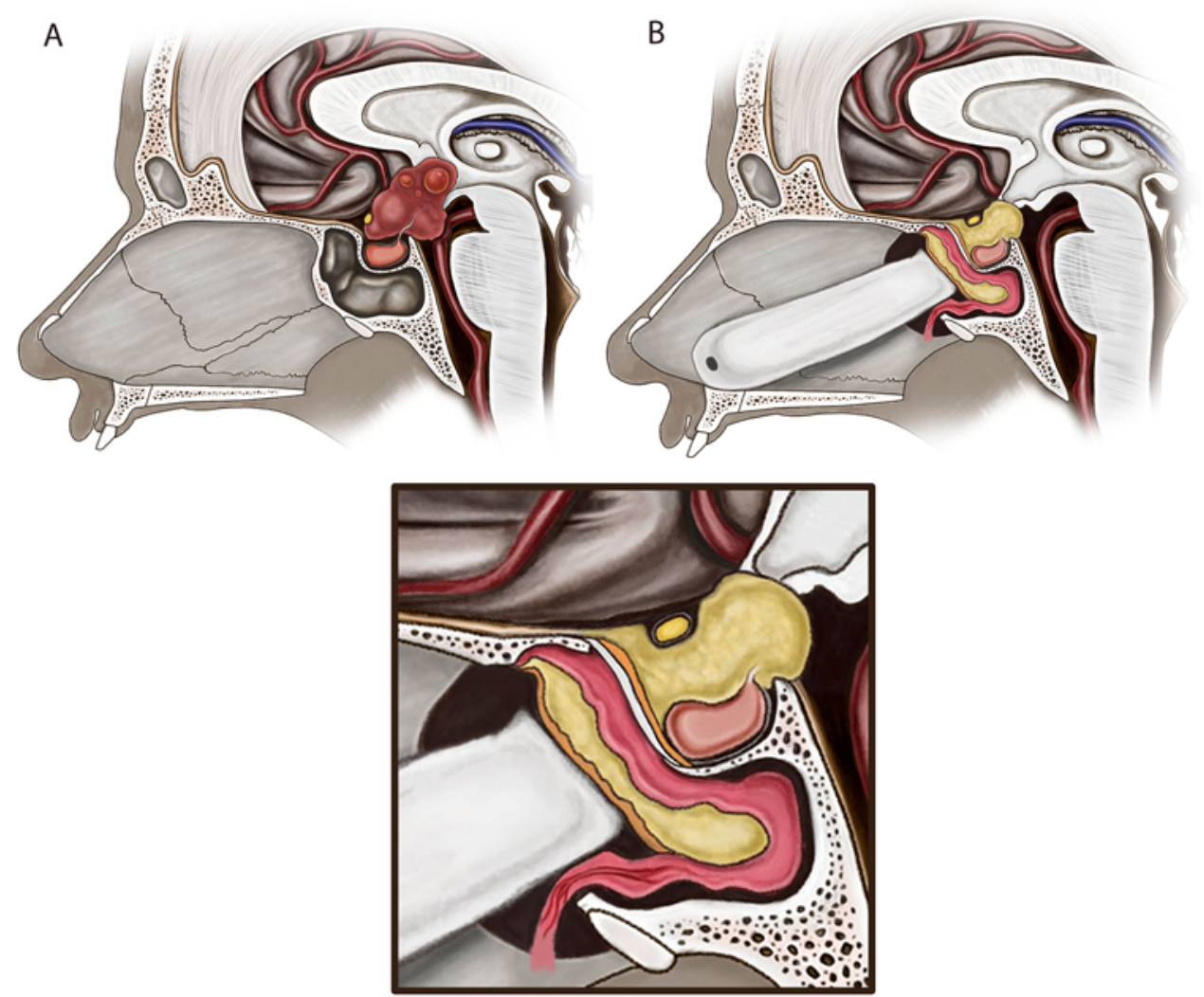

FIG. 2. Artist's depiction of retrochiasmal craniopharyngioma (A) and repair of grade 3 CSF leak using multilayered reconstruction after tumor removal (B, with enlarged view in image at bottom of figure). Repair materials, from deep to superficial, include abdominal fat graft, collagen sponge, septal bone graft, nasal septal flap, and additional fat over nasoseptal flap, followed by outer layer of collagen sponge and tissue glue (not shown). The entire repair construct is held in position by bilateral soft temporary buttress (Merocel). Copyright DF Kelly Neurosurgical Inc. Published with permission.

to obliterate any dead space (performed in $97 \%$ of cases of grade 2 leak in this series). The anterior sellar dura is returned to its anatomical position, and collagen sponge is layered over the sella and adjacent sphenoid. In a majority of cases (63\% in this series), a harvested bony buttress or less frequently a synthetic buttress (e.g., Medpor TSI) is wedged into the intrasellar extradural space (Fig. 4). If adjacent mucosa is available, it is also layered back over the sella. If a solid buttress is not available or cannot be wedged, then additional fat is placed in the posterior sphenoid sinus against the sellar reconstruction, followed by another layer of collagen sponge followed by tissue glue. If no bony or synthetic buttress has been placed, then single or bilateral temporary Merocel sponges are placed for 5 days.

\section{Grade 3 (large CSF leak)}

For transsellar-transplanum or transsellar-transclival approaches, the sellar, suprasellar, or clival resection cavity is filled with abdominal fat (performed in $100 \%$ of cases of grade 3 leak in this series). In patients undergoing resection of craniopharyngiomas (Figs. 2 and 5) or tuberculum sellae meningiomas, the fat is placed directly in the sellar and/or supraglandular space with care taken not to injure the superior hypophyseal arteries or infundibulum, which are frequently in the surgical field. In patients undergoing resection of clival chordomas or other clival le- sions with intradural extension, fat is gently placed against the brainstem. Fat placement should fill the dead space but not create undue mass effect upon the optic apparatus or brainstem. Next, collagen sponge is placed over the dural defect extending only 1-2 $\mathrm{mm}$ beyond the bony edges of the surgical corridor; this placement allows maximal contact of the flap with the bone around the defect. Following placement of collagen, the skull base defect is frequently (in 56\% of grade 3 leaks in this series) covered by a bony (or synthetic buttress) that maximally fills the defect. This buttress is sometimes wedged into the epidural space; however, wedging is not essential given the other layers of repair. The nasoseptal flap (or middle turbinate flap) is then rolled into the sphenoid sinus with care being taken to ensure all sphenoid sinus mucosa has been removed. The flap should fully cover the defect and extend beyond its edges as far as possible with maximal contact on the bone adjacent to the defect. Additional fat is placed over the flap followed by an outer layer of collagen sponge and tissue glue followed by temporary bilateral Merocel sponges placed under direct visualization, which are removed after 5 days.

\section{Repair Protocol Modifications Over Time}

Changes in the repair protocol were evaluated over the 7-year period, including construct materials used and 


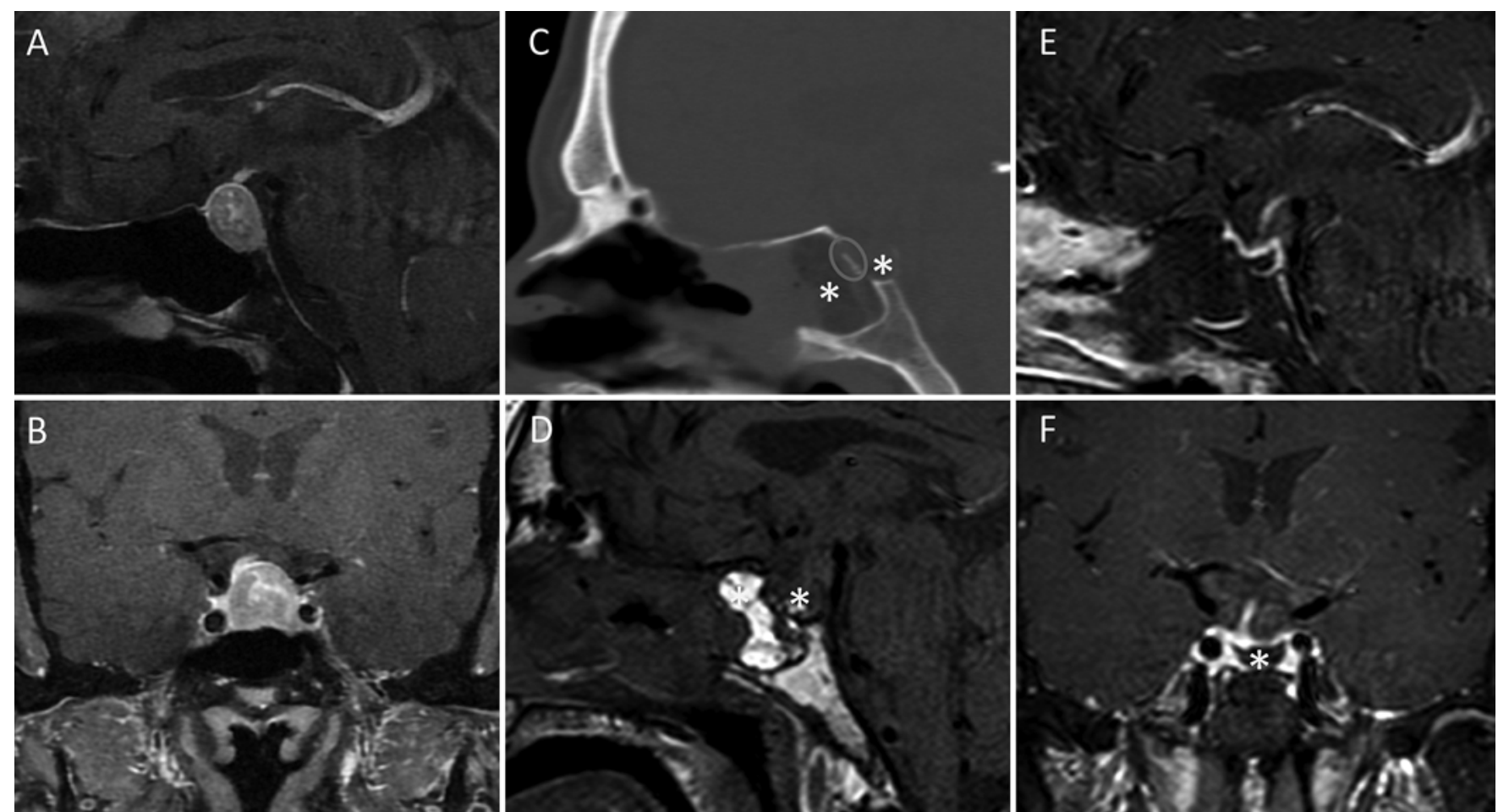

FIG. 3. Endocrine-inactive adenoma and grade 1 CSF leak in a 65-year-old man with hypothyroidism and hypogonadism. A and B: Preoperative Gd-enhanced sagittal (A) and coronal (B) T1-weighted MR images. C: Postoperative sagittal reconstruction CT scan obtained 1 hour after surgery. D: POD 1 sagittal noncontrast T1-weighted MR image. E and F: POD 1 Gd-enhanced sagittal (E) and coronal (F) T1-weighted MR images with fat suppression. The adenoma (A and B) was removed in gross-total fashion. Skull base repair was accomplished with intrasellar fat graft (asterisks), collagen sponge, then intrasellar extradural septal bone graft (oval) followed by sphenoid sinus fat graft, second layer of collagen sponge, and Tisseel glue (C-F).

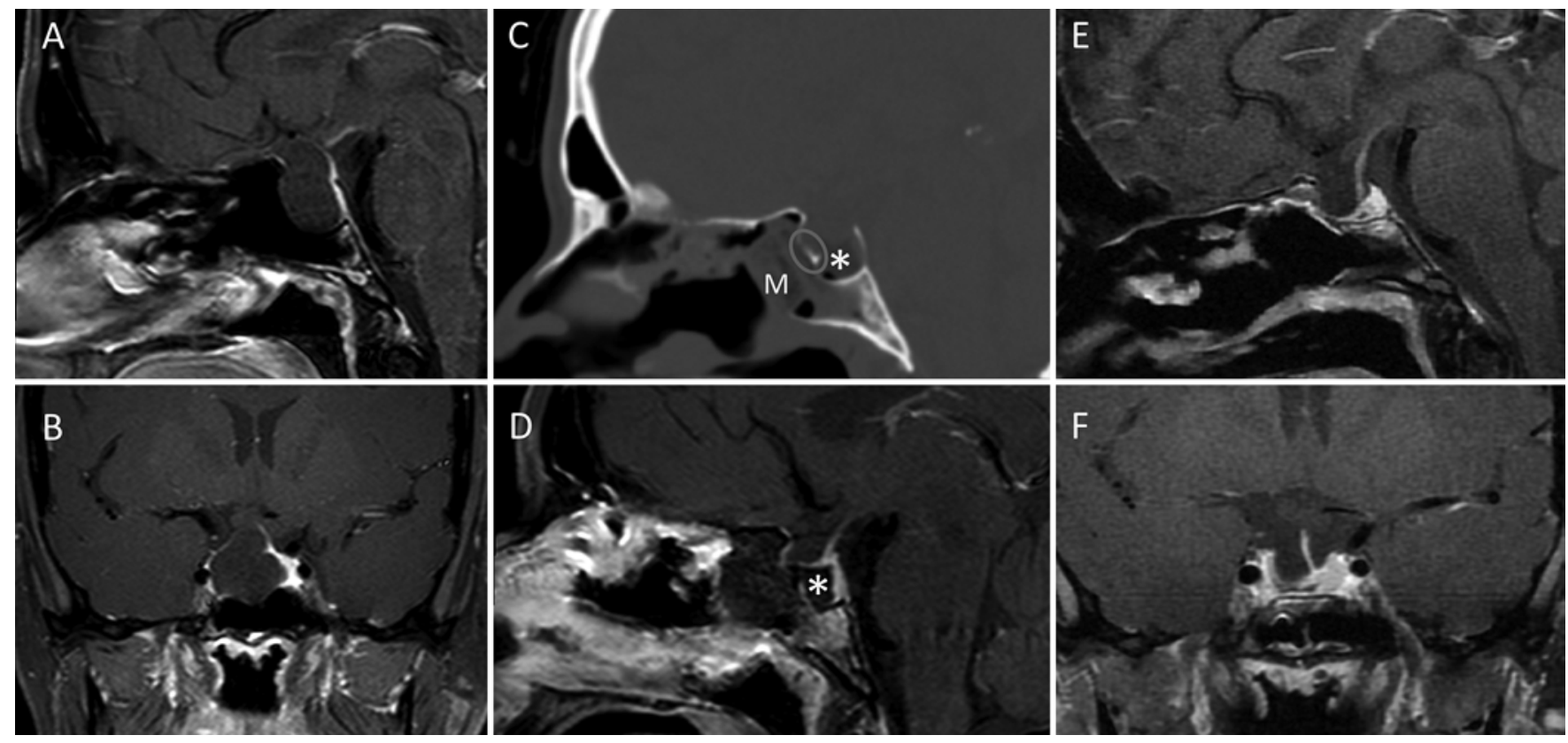

FIG. 4. Sellar arachnoid cyst and grade 2 CSF leak in a 32-year-old woman with progressive headaches and fatigue, and imaging evidence of cyst enlargement (A and B). A and B: Preoperative Gd-enhanced sagittal (A) and coronal (B) T1-weighted MR images. C: Postoperative sagittal reconstruction CT scan obtained 1 hour after surgery. D: Postoperative Gd-enhanced sagittal T1weighted MR image. E and F: Follow-up Gd-enhanced sagittal (E) and coronal (F) T1-weighted MR images obtained 19 months after the operation. The patient underwent sellar cyst decompression and skull base repair with intrasellar abdominal fat graft, collagen sponge, and intrasellar extradural septal bone graft wedged horizontally (oval), then additional sphenoid sinus fat graft and a second layer of collagen sponge, followed by Tisseel glue and a single Merocel buttress placed fully within the sphenoid sinus ( $C$ and $D)$. At 19 months after surgery, she is doing well with no endocrinopathy and complete cyst involution $(E$ and $F)$. The asterisks indicate fat graft. $\mathrm{M}=$ Merocel buttress. 

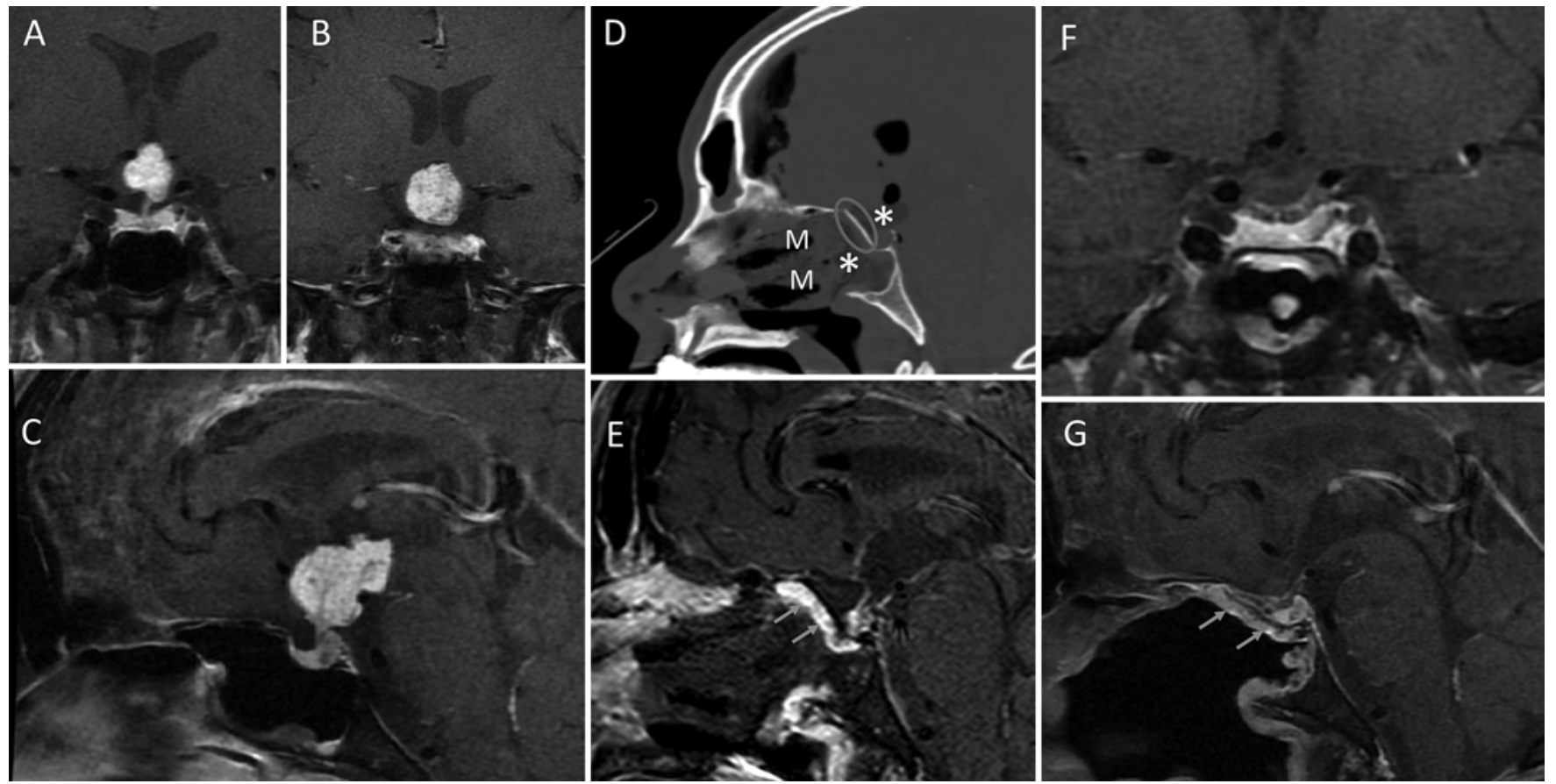

FIG. 5. Craniopharyngioma and grade 3 CSF leak in a 56-year-old man with decreased vision (5 months), hypothyroidism, and hypogonadism. A-C: Preoperative Gd-enhanced coronal (A and B) and sagittal (C) T1-weighted MR images. D: Postoperative sagittal reconstruction of CT scan obtained 1 hour after the operation. E: POD 1 sagittal Gd-enhanced T1-weighted MR image. F and G: Follow-up Gd-enhanced coronal $(F)$ and sagittal $(G)$ MR images obtained 8 months after the operation. The retrochiasmal tumor (A-C) was removed in gross-total fashion via transellar-transplanum route. Skull base repair was accomplished with supraglandular fat graft (*), collagen inlay, and septal bone graft wedged vertically (oval), followed by nasoseptal flap (arrows), additional sphenoid sinus fat, an outer layer of collagen, Tisseel, and bilateral Merocel sponges (M). The 8-month follow-up MR images (F and $\mathrm{G}$ ) show no tumor recurrence and enhancing nasoseptal flap.

adjuvant measures, such as placement of lumbar drains, as well as antibiotic regimen. The cohort timeline was divided into 2 epochs: April 2010 through August 2013 (261 operations), and September 2013 through April 2017 (290 operations). While somewhat arbitrary, this dividing line was chosen given that there was a cluster of 3 meningitis cases and 1 postoperative CSF leak in early 2013, prompting a change in our protocol resulting in alterations of buttress utilization and perioperative antibiotic administration. Specifically, a more frequent use of permanent and temporary buttress placement was adopted. A review of our prior antibiotic regimen identified that missed intraoperative antibiotic dosing may have been a contributing factor for certain cases of postoperative meningitis. Hence, we instituted a well-defined and strict repair and antibiotic regimen in September 2013. The antibiotic regimen used in the second epoch of the series (and currently in use) includes re-dosing of intravenous antibiotics for cases lasting over 6 hours. Specific antibiotics included are ampicillin/sulbactam $3 \mathrm{~g}$, dosed appropriately for renal function. For patients with penicillin or cephalosporin allergies, clindamycin was administered. For patients without nasal packing, the duration of antibiotic treatment was only 24 hours after surgery. For patients with nasal packing, the regimen was converted to oral antibiotic equivalents after the initial 24-hour period until the nasal packs were removed-typically on postoperative day (POD) 5 .

\section{Postoperative Surveillance for CSF Leaks}

In the great majority of patients with an intraoperative CSF leak, a CT scan is typically performed shortly after surgery on the day of surgery and a pituitary MRI study (with and without gadolinium) is performed on the morning of POD 1. On both CT and MRI, the integrity of the repair construct is assessed, including location of fat graft, bone grafts, vascular flaps (if used), and nasal/sphenoid Merocel buttress, and the degree (if any) of pneumocephalus is also assessed. All patients also have a provocative "tilt test" performed prior to hospital discharge (typically POD 2) to assess for rhinorrhea. While sitting up, patients are asked to tilt their head down with the nose in a dependent position for approximately 30 seconds. A repair failure with CSF rhinorrhea is typically obvious, manifested as a persistent watery drip from one or both nostrils, whereas thicker, mucus-like drainage does not constitute CSF rhinorrhea. When the patients are seen for their initial postoperative otolaryngology appointment and nasal debridement (typically on POD 5-6 if a temporary Merocel buttress is in place; or on POD 8-10 if no Merocel is in place), they are also assessed endoscopically at that time for evidence of rhinorrhea or repair construct breakdown.

\section{Data Analysis}

Rates of repair failure and meningitis were compared 
TABLE 2. Patient cohort of endonasal endoscopic tumor or cyst removal April 2010-April 2017

\begin{tabular}{lc}
\hline \multicolumn{1}{c}{ Characteristic } & Value \\
\hline Total no. of patients (55\% female) & 509 \\
\hline Age in yrs & 50 \\
\hline Median & $7-92$ \\
\hline Range & $109(21.4 \%)$ \\
\hline No. of patients w/ prior surgery & \\
\hline Pathology & $65.7 \%$ \\
\hline Pituitary adenoma & $7.1 \%$ \\
\hline Rathke's cleft cyst & $6.4 \%$ \\
\hline Meningioma & $4.5 \%$ \\
\hline Craniopharyngioma & $2.4 \%$ \\
\hline Arachnoid cyst & $2.0 \%$ \\
\hline Chordoma & $12 \%$ \\
\hline Other* & 551 \\
\hline Total no. of ops & $225(41 \%)$ \\
\hline No. of extended approaches
\end{tabular}

* "Other" includes olfactory neuroblastoma, sinonasal carcinoma, mucosal melanoma, schwannoma, sarcoma, metastasis, chondroma, dermoid cyst, lymphoma, spindle cell neuroendocrine tumor, fibrous dysplasia, cholesterol granuloma, cavernous hemangioma, hemangiopericytoma, neurocytoma, Langerhans histiocytosis, oncocytoma, and granuloma.

between various groups (different grades, different pathologies, different time periods, etc.). The change in time repair failure and meningitis over time epochs was also assessed. Statistical analysis was performed utilizing chi-square statistics or the Fisher's exact test. Comparing BMI in patients with postoperative CSF leaks and without, we used estimated BMI in 2 patients (with postoperative leaks) from clinic notes, and in all others with data from the electronic medical record, using a calculated BMI from height and weight beginning in July 2014. SPSS software was used for these analyses (v. 13, IBM Corp.); $\mathrm{p}<$ 0.05 was considered statistically significant.

\section{Results}

\section{Cohort Characteristics}

From April 2010 through April 2017, 509 consecutive patients $(55 \%$ women; median age 50 years, range 7-92 years) underwent endonasal endoscopic tumor or cyst removal for a total of 551 operations (Table 2). Of these patients, 109 (21\%) had prior surgery elsewhere and 41 (8\%) had more than 1 operation at Providence Saint John's Health Center. Extended transsphenoidal approaches (transplanum, transclival, lateral approaches to the cavernous sinus, or a combination of extended approaches) were used for parasellar pathologies in 225 cases (41\%).

\section{Intraoperative CSF Leaks by Grade and Pathology}

Of all 551 procedures, 267 (48\%) had no intraoperative leak (grade 0) and $284(52 \%)$ had a recognized leak, including $103(19 \%)$ grade 1, 98 (18\%) grade 2, and $83(15 \%)$ grade 3 leaks (Table 3). As shown in Fig. 6, by pathology, craniopharyngioma and microadenoma operations had the highest and lowest grade 3 leak rates $(87.5 \%$ vs $2.5 \%)$, respectively.

\section{Repair Materials Used for Skull Base Reconstruction}

As shown in Fig. 1, reconstruction materials included collagen matrix in over $98 \%$ of all repairs and tissue glue in $74 \%$ of grade 0 repairs (no CSF leak) and in $99 \%-100 \%$ of all grade 1-3 CSF leaks. An abdominal fat graft was used in increasing frequency from $33 \%$ to $84 \%$ to $97 \%$ to $100 \%$ for grade $0,1,2$, and 3 leaks, respectively. Pedicled flaps were used in 12 of $468(2.6 \%)$ grade 0,1 , and 2 leaks and in 66 of $83(79.5 \%)$ grade 3 leaks $(72.3 \%$ nasoseptal flaps, $7.2 \%$ middle turbinate flaps). Lumbar drains for CSF diversion were used in 4 patients early in the series, all for grade 3 leaks repaired with fat, collagen, nasoseptal flaps, and temporary buttresses. Pathology included tuberculum meningioma, craniopharyngioma, arachnoid cyst, and chordoma. None of the 4 patients had a repair failure but $1(25 \%)$ developed postoperative meningitis.

There were 3 fat graft site-related complications-1 hematoma requiring reoperation, 1 infection requiring debridement and antibiotics, and 1 ventriculoperitoneal shunt catheter inadvertently cut during the harvesting of fat, requiring an uneventful repair of the distal end of the shunt.

\section{Postoperative CSF Leaks by Grade and Pathology}

Postoperative CSF leak repair failures occurred in 9 of $551(1.6 \%)$ cases overall and in 9 of 284 (3.2\%) cases with a grade 1,2, or 3 leak combined. By leak grade the repair failure rate was 0 for grade 0 leaks, $2(1.9 \%)$ for grade 1 leaks, 3 (3.1\%) for grade 2 leaks, and 4 (4.8\%) for grade 3 leaks (Tables 3-5).

As shown in Table 4, the repair failure rate was highest in craniopharyngioma cases (total 8\%, 2 of 25 cases; for

TABLE 3. Intraoperative CSF leak rate, repair failures, and meningitis by grade in 551 operations

\begin{tabular}{cccccc}
\hline & & \multicolumn{3}{c}{ Repair Failures } & \multirow{2}{*}{ Meningitis (\%) } \\
\cline { 3 - 5 } CSF Leak Grade & Ops (\%) & Total (\%) & Pre-Protocol & Post-Protocol & $0 / 267$ \\
\hline Grade 0 & $267(48 \%)$ & 0 & $0 / 118$ & $0 / 149$ & $1 / 103(1 \%)$ \\
\hline Grade 1 & $103(19 \%)$ & $2(1.9 \%)$ & $1 / 52(1.9 \%)$ & $1 / 51(2 \%)$ & $1 / 98(1 \%)$ \\
\hline Grade 2 & $98(18 \%)$ & $3(3.1 \%)$ & $2 / 57(3.5 \%)$ & $1 / 41(2.4 \%)$ & $4 / 83(4.8 \%)$ \\
\hline Grade 3 & $83(15 \%)$ & $4(4.8 \%)$ & $3 / 34(8.8 \%)$ & $1 / 49(2 \%)$ & $6 / 551(1.1 \%)$ \\
\hline Total & $551(100 \%)$ & $9(1.6 \%)$ & $6 / 261(2.3 \%)$ & $3 / 290(1 \%)$ & \\
\hline
\end{tabular}

Total repair failures of grade 1-3 leaks: 9/284 (3.2\%). 


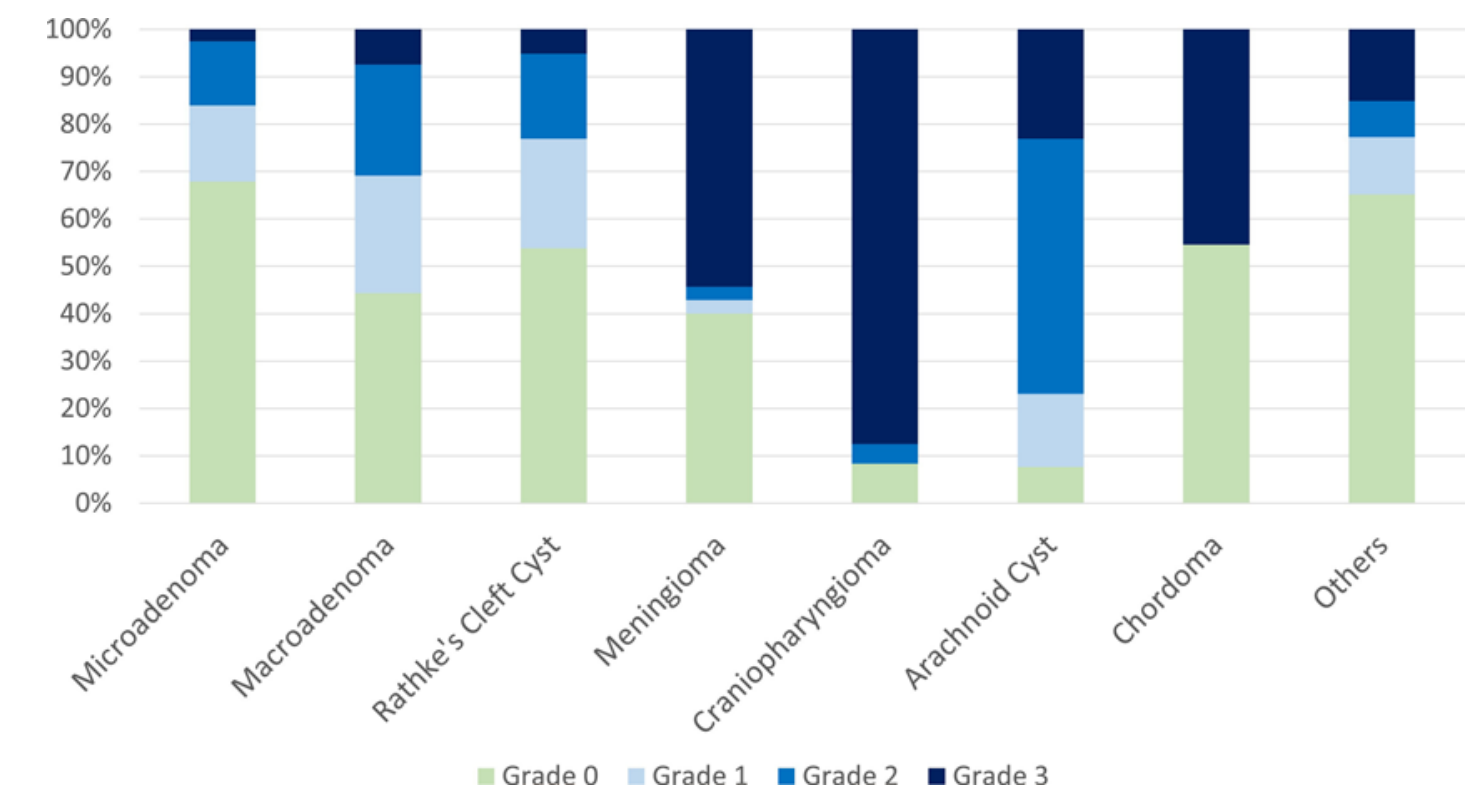

FIG. 6. Intraoperative CSF leak rate by pathology in 551 operations.

grade 1, 2, and 3 leaks, 2/23 [8.7\%]) and sellar arachnoid cyst cases (total 7.7\%, 1 of 13 cases; for grade 1, 2, and 3 leaks, $1 / 12$ [8.3\%]) and lower in parasellar meningiomas (4.8\% for grade 1, 2, and 3 leaks) and pituitary adenomas ( $2.7 \%$ for grade 1,2 , and 3 leaks); there were no repair failures in 39 Rathke's cleft cyst or 11 clival chordoma operations. There have been no repair failures in the last 122 consecutive cases of the series.

\section{Postoperative Meningitis by Grade and Pathology}

As shown in Tables 3, 4, and 6, postoperative bacterial meningitis occurred in 6 operations $(1.1 \%$ overall and $2.1 \%$ for operations with grade 1,2, and 3 leaks), including 2 of 23 operations for craniopharyngioma resection $(8.7 \%$, both grade 3 leaks), 2 of 21 for meningioma resection $(9.5 \%$, both grade 3 leaks), and 2 of 183 for pituitary adenoma re-

TABLE 4. Intraoperative CSF leak rate, repair failures, and meningitis by pathology in 551 operations

\begin{tabular}{lcccc}
\hline \multicolumn{1}{c}{ Pathology } & $\begin{array}{c}\text { Intraop } \\
\text { No. of } \\
\text { Cases }\end{array}$ & $\begin{array}{c}\text { Leaks }(\%) \\
\text { Grades 1-3 }\end{array}$ & $\begin{array}{c}\text { Failures }(\%) \\
\text { in Grades } \\
1-3\end{array}$ & $\begin{array}{c}\text { Meningitis } \\
(\%) \text { in } \\
\text { Grades } \\
1-3\end{array}$ \\
\hline Pituitary adenoma & 362 & $183(50.4 \%)$ & $5(1.4 \%)$ & $2(1.1 \%)$ \\
\hline \multicolumn{1}{c}{ Macro } & 281 & $156(55.5 \%)$ & $4(1.4 \%)$ & $1(0.6 \%)$ \\
\hline \multicolumn{1}{c}{ Micro } & 81 & $26(32.1 \%)$ & $1(1.2 \%)$ & $1(3.8 \%)$ \\
\hline Rathke's cleft cyst & 39 & $18(46.2 \%)$ & $0(0.0 \%)$ & $0(0.0 \%)$ \\
\hline Meningioma & 35 & $21(60.0 \%)$ & $1(2.9 \%)$ & $2(9.5 \%)$ \\
\hline Craniopharyngioma & 25 & $23(92.0 \%)$ & $2(8.0 \%)$ & $2(8.7 \%)$ \\
\hline Arachnoid cyst & 13 & $12(92.3 \%)$ & $1(7.7 \%)$ & $0(0.0 \%)$ \\
\hline Chordoma & 11 & $5(45.5 \%)$ & $0(0.0 \%)$ & $0(0.0 \%)$ \\
\hline Other pathology & 66 & $23(34.8 \%)$ & $0(0.0 \%)$ & $0(0.0 \%)$ \\
\hline
\end{tabular}

section (1.1\%, 1 grade 1 leak and 1 grade 2 leak). Only 2 of 6 patients with meningitis had an associated repair failure and postoperative CSF leak: one of these 2 patients was undergoing resection of a petroclival meningioma and had a grade 3 intraoperative leak and a delayed (POD 12) leak, and the other was undergoing resection of a pituitary adenoma and had a grade 1 intraoperative leak and a delayed leak (POD 6) that was treated with lumbar drain placement. In all 6 cases the patients recovered uneventfully from their meningitis after antibiotic therapy, without sequelae such as hydrocephalus or other complications.

\section{CSF Leak Repair Failure Detection and Treatment}

As detailed in Table 5, 5 of 9 repair failures were detected in hospital from POD 1 to POD 6. Detection of these failures resulted from observance of CSF rhinorrhea and/or imaging with CT or MRI showing fat graft migration out of the sella and/or increased or new pneumocephalus. Four of 9 repair failures were detected after hospital discharge; in all 4 of these cases, the patients had a negative tilt test prior to discharge home. Detection of these repair failures resulted from clinical suspicion (details in Table 5). Of these 9 repair failures, 8 were effectively treated with urgent reoperation and 1 with lumbar CSF diversion for 2 days. In the 7 patients without a nasoseptal flap used at their initial surgery, none had a nasoseptal flap used for their CSF leak re-repair.

\section{Risk Factors for Repair Failure}

As shown in Table 5, of the 9 postoperative CSF leaks, likely contributing factors and/or technical errors associated with repair failure were $\mathrm{BMI} \geq 30(7 / 9)$, lack of a rigid or soft buttress (4/9), grade 3 leak (4/9), severe postoperative bucking on ventilator or vomiting (4/9), non-use of a nasoseptal flap in 2 of 4 grade 3 leaks, and 2 patients who had intraoperative diaphragma sellae herniation into 
TABLE 5. Characteristics of 9 patients with postoperative CSF leak, including risk factors

\begin{tabular}{|c|c|c|c|c|c|c|c|c|c|}
\hline Pathology & $\begin{array}{l}\text { Age } \\
\text { (yrs), } \\
\text { Sex }\end{array}$ & Year & BMI & $\begin{array}{l}\text { Leak } \\
\text { Grade }\end{array}$ & POD & CSF Leak Detection & $\begin{array}{l}\text { Potential Risk Factors \& } \\
\text { Technical Errors }\end{array}$ & Meningitis & Treatment \\
\hline $\begin{array}{l}\text { Macroadenoma, } \\
\text { inactive }\end{array}$ & $70, F$ & 2010 & 22 & 1 & 1 & $\begin{array}{l}\text { New pneumocephalus } \\
\text { on MRI }\end{array}$ & Severe vomiting, no buttress & No & Revise repair \\
\hline Craniopharyngioma & $55, M$ & 2010 & 33 & 3 & 12 & Spontaneous rhinorrhea & BMI, grade 3 leak, no nasoseptal flap & No & Revise repair \\
\hline Craniopharyngioma & $42, M$ & 2011 & 31 & 3 & 1 & Graft migration on $\mathrm{CT}$ & BMI, grade 3 leak, severe vomiting & No & Revise repair \\
\hline $\begin{array}{l}\text { Microadenoma, } \\
\text { Cushing's }\end{array}$ & $48, F$ & 2011 & 32 & 2 & 2 & Rhinorrhea on tilt test & $\mathrm{BMI}, \mathrm{CD}$, inadequate buttress & No & Revise repair \\
\hline $\begin{array}{l}\text { Macroadenoma, } \\
\text { inactive }\end{array}$ & $53, M$ & 2012 & 32 & 2 & 6 & $\begin{array}{l}\text { Rhinorrhea after pack re- } \\
\text { moval; graft migration } \\
\text { seen on POD O CT }\end{array}$ & $\begin{array}{l}\text { BMI, diaphragma sellae herniation } \\
\text { into sphenoid }\end{array}$ & No & Revise repair \\
\hline $\begin{array}{r}\text { Meningioma, } \\
\text { petroclival }\end{array}$ & $52, \mathrm{M}$ & 2013 & 24 & 3 & 12 & $\begin{array}{l}\text { New pneumocephalus } \\
\text { on CT, fever, HA }\end{array}$ & Grade 3 leak, severe vomiting & Yes & Revise repair \\
\hline $\begin{array}{l}\text { Macroadenoma, } \\
\text { inactive }\end{array}$ & $67, F$ & 2014 & 30 & 1 & 6 & $\begin{array}{l}\text { Rhinorrhea after pack } \\
\text { removal }\end{array}$ & BMI & Yes & Lumbar drain \\
\hline $\begin{array}{l}\text { Macroadenoma, } \\
\text { Cushing's }\end{array}$ & $59, \mathrm{~F}$ & 2014 & 36 & 3 & 6 & & $\begin{array}{l}\text { BMI, grade } 3 \text { leak, no nasoseptal } \\
\text { flap, diaphragma sellae herniation } \\
\text { into sphenoid, no Merocel buttress }\end{array}$ & No & Revise repair \\
\hline $\begin{array}{l}\text { Sellar arachnoid } \\
\text { cyst }\end{array}$ & $28, F$ & 2015 & 31 & 2 & 0 & $\begin{array}{l}\text { New pneumocephalus \& } \\
\text { graft migration on CT }\end{array}$ & $\begin{array}{l}\text { BMI, severe bucking on ventilator, no } \\
\text { Merocel buttress }\end{array}$ & No & Revise repair \\
\hline
\end{tabular}

$\mathrm{CD}=$ Cushing's disease; $\mathrm{HA}=$ headache .

the sphenoid sinus after tumor removal and prior to repair (Table 5). Eight of 9 patients had at least 2 of the following risk factors: high BMI, grade 3 leak, severe vomiting or bucking on ventilator, and/or no buttress. Overall, 5 of the 9 repair failures can be largely attributed to technical errors of the repair, including failure to use a buttress or an adequate buttress in 4 patients, and not using a nasoseptal flap in 2 of 4 grade 3 leaks. Both patients with nasoseptal flap failures requiring reoperation (cases 3 and 6 in Table 5 ) had grade 3 leaks, with severe vomiting around the time of their leak development, and one had a high BMI.
Univariate analyses were performed for several risk factors, including intraoperative leaks, pathology, BMI, and lumbar drain usage. Any intraoperative CSF leak (grades $1-3)$ versus no leak (grade 0 ) was predictive of postoperative CSF leak $(\mathrm{p}=0.005)$. However, comparing the different CSF leak groups (e.g., grade 1 vs grade 2 vs grade 3 or grades 1 and 2 vs grade 3 ) did not demonstrate significant differences in postoperative leak rates. Regarding pathology, although the rate of postoperative CSF leak rate was highest in patients with grade 1-3 leaks and meningiomas, craniopharyngiomas, and arachnoid cysts (4/56

TABLE 6. Characteristics of 6 patients with meningitis, including risk factors

\begin{tabular}{|c|c|c|c|c|c|c|c|c|c|c|c|c|}
\hline Pathology & $\begin{array}{l}\text { Age } \\
\text { (yrs), } \\
\text { Sex }\end{array}$ & $\mathrm{Yr}$ & BMI & $\begin{array}{l}\text { Preop } \\
\text { Sinusitis }\end{array}$ & $\begin{array}{l}\text { Leak } \\
\text { Grade }\end{array}$ & $\begin{array}{l}\text { Nasoseptal } \\
\quad \text { Flap }\end{array}$ & $\begin{array}{l}\text { Long Op } \\
\text { Time }\end{array}$ & $\begin{array}{c}\text { Only } 1 \\
\text { Dose of } \\
\text { Intraop ABx }\end{array}$ & $\begin{array}{l}\text { Postop } \\
\text { CSF } \\
\text { Leak }\end{array}$ & $\begin{array}{c}2 \text { Ops for } \\
\text { Residual } \\
\text { Tumor }\end{array}$ & $\begin{array}{l}\text { Intraop } \\
\text { Lumbar } \\
\text { Drain }\end{array}$ & CSF Culture \\
\hline Craniopharyngioma & $33, F$ & 2012 & 21 & No & 3 & Yes & $\begin{array}{l}\text { Yes (9 hrs, } \\
14 \text { mins) }\end{array}$ & Yes & No & No & Yes & $\begin{array}{l}\text { Neisseria } \\
\text { lactamica }\end{array}$ \\
\hline $\begin{array}{l}\text { Petroclival menin- } \\
\text { gioma }\end{array}$ & $54, \mathrm{M}$ & 2013 & 24 & No & 3 & Yes & $\begin{array}{l}\text { Yes (7 hrs, } \\
58 \text { mins) }\end{array}$ & Yes & Yes & No & No & MSSA \\
\hline $\begin{array}{l}\text { Microadenoma, } \\
\text { Cushing's }\end{array}$ & $44, F$ & 2013 & 26 & No & 2 & No & $\begin{array}{l}\text { No (2 hrs, } \\
21 \text { mins) }\end{array}$ & No & No & $\begin{array}{l}\text { Yes ( } 9 \text { days } \\
\text { apart) }\end{array}$ & No & $\mathrm{Neg}$ \\
\hline $\begin{array}{l}\text { Macroadenoma, } \\
\text { inactive }\end{array}$ & $67, \mathrm{~F}$ & $2014 \dagger$ & 29 & No & 1 & No & $\begin{array}{l}\text { No (3 hrs, } \\
10 \text { mins) }\end{array}$ & No & Yes & No & No & Neg \\
\hline
\end{tabular}

$\mathrm{ABx}=$ antibiotics; mins = minutes; neg = negative; $\mathrm{MSSA}=$ methicillin-sensitive Staphylococcus aureus .

* Prior surgery and radiotherapy.

$\dagger$ Surgery was performed after institution of formal antibiotic protocol, which began in September 2013. 
TABLE 7. Use of nasoseptal flaps by pathology, grade, and failure rate

\begin{tabular}{lrrrc}
\hline \multicolumn{1}{c}{ Pathology } & $\begin{array}{c}\text { No. of } \\
\text { Ops }\end{array}$ & $\begin{array}{c}\text { Nasoseptal } \\
\text { Flaps }\end{array}$ & $\begin{array}{r}\% \text { Grade } 3 \\
\text { Leaks }\end{array}$ & $\begin{array}{c}\text { Failure Rate for } \\
\text { Grade 3 Leaks* }\end{array}$ \\
\hline Craniopharyngioma & 25 & $20(80 \%)$ & $19(95 \%)$ & $1(5 \%)$ \\
\hline Chordoma & 11 & $7(64 \%)$ & $5(71 \%)$ & 0 \\
\hline Meningioma & 35 & $19(54 \%)$ & $18(95 \%)$ & $1(5.5 \%)$ \\
\hline Arachnoid cyst & 13 & $2(15 \%)$ & $100 \%$ & 0 \\
\hline Pituitary adenoma & 362 & $8(2.2 \%)$ & $100 \%$ & 0 \\
\hline Rathke's cleft cyst & 39 & $1(3 \%)$ & $100 \%$ & 0 \\
\hline Other pathology & 66 & $9(14 \%)$ & $7(78 \%)$ & 0 \\
\hline Total & 551 & $66(12 \%)$ & $62(92.5 \%)$ & $2(3.2 \%)$ \\
\hline
\end{tabular}

* Last nasoseptal flap failure: January 2013 (number 19 of 66 ). No failures in 6 grade 0,1 , or 2 leak repairs.

[7.1\%]), the increase was not significant compared with all other pathologies $(5 / 229$ [2.2\%]) $(\mathrm{p}=0.57)$. Regarding mean BMI, there was no significant difference between the 9 patients with postoperative CSF leaks and the most recent 209 patients in the series without a postoperative leak (mean BMI $29.1 \pm 4.3$ vs $28.1 \pm 5.9$, respectively; $p$ $=0.63$ ). Use of a lumbar drain was not associated with a lower leak rate $(\mathrm{p}=0.79)$.

\section{Risk Factors for Meningitis}

As shown in Table 6, in the 6 patients with bacterial meningitis, risk factors included intraoperative CSF leak in all 6 patients (4 grade 3,1 grade 2, 1 grade 1), postoperative CSF leak preceding meningitis in 2 patients, prolonged operations and missed repeat intraoperative antibiotic dosing in 4 patients (mean operative time 8 hours and 10 minutes), repeat operation for residual tumor within same hospitalization in 2 patients, and prior surgery and proton beam radiation in 1 patient. The presence of any intraoperative CSF leakage was associated with postoperative meningitis ( $\mathrm{p}=0.017)$, and postoperative CSF leakage was associated with the development of meningitis as well ( $28.6 \%$ vs $0.007 \%, p=0.005)$. Patients with intraoperative CSF leaks and perioperative lumbar drain placement had a higher rate of meningitis than those without a lumbar drain ( $25 \%$ vs $1.8 \%, \mathrm{p}=0.18$ ), although the difference was not statistically significant. CSF leak grade, tumor type, and epoch of surgery were not predictive of meningitis. The last case of bacterial meningitis was in 2014; none have occurred in the last 232 operations of the series.

\section{Use of Pedicled Nasoseptal or Middle Turbinate Flaps}

As shown in Table 7, a nasoseptal flap was used in 12\% of all operations, including $2 \%$ of pituitary adenoma resections and $80 \%$ of craniopharyngioma resections. There were 2 nasoseptal flap repair failures (3\%), and none in the last 47 nasoseptal flaps in the series; none of the 12 middle turbinate flaps failed, including in 6 grade 3 leaks. In 20 pituitary adenoma patients with grade 3 leaks, nasoseptal flaps were used in 8 and middle turbinate flaps in 2 . These 10 patients all had large invasive tumors (mean maximum tumor diameter of $35 \pm 8 \mathrm{~mm}$ ), and 4 of these 10 had giant adenomas; 8 of 20 had tumor extending through and above the diaphragma sellae, and 8 of 10 had an extended transellar-transplanum approach. Among these 20 adenoma patients, there were no repair failures in the 10 patients in whom pedicled flaps were used, but there was 1 repair failure $(10 \%)$ in the 10 patients in whom a pedicled flap was not used.

\section{Repair Failures and Meningitis Over Time and Protocol Modifications}

As shown in Fig. 7, in comparing the first and second epochs of the series (261 operations from April 2010 through August 2013 and 290 operations from September 2013 to April 2017), there were $6(2.3 \%)$ repair failures in the earlier epoch and $3(1.0 \%)$ in the second epoch $(p=0.24)$. This decrease in repair failures was greatest for grade 3 leaks, decreasing from $9 \%$ (3 of 34$)$ to $2 \%(1$ of 49$)(p=0.16$ ). The incidence of postoperative meningitis, decreased from $5(1.9 \%)$ cases to $1(0.3 \%)(\mathrm{p}=0.079)$. Three repair adjuncts were phased out entirely by 2012: perioperative lumbar drains (used in only 4 patients $[<1 \%]$ ), titanium mesh (used in 9 patients [1.6\%]), and Bioglue surgical adhesive (Cryolife, Inc.; used in only 2 patients $[<1 \%]$ ). In comparing the periods before and after protocol implementation, several additional significant differences in repair construct were noted. As shown in Fig. 8, for all CSF leak grades use of permanent rigid buttress (bone or synthetic) increased, most notably in grade $1(13 \%$ to $55 \%, \mathrm{p}<0.001)$ and grade 3 leaks ( $32 \%$ to $76 \%, \mathrm{p}<0.001)$. For grade 1,2 , and 3 leaks combined, use of autologous bone as a permanent buttress

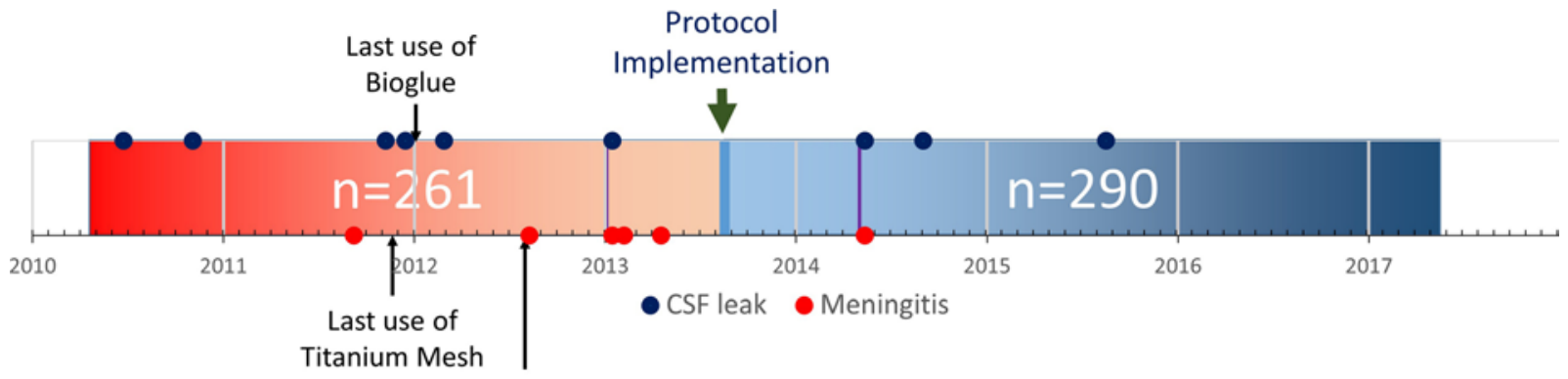

Last use of

Lumbar Drain

FIG. 7. Repair failures and meningitis over time and protocol modifications. The pre-protocol period included 261 operations, and the protocol period included 290 operations. 


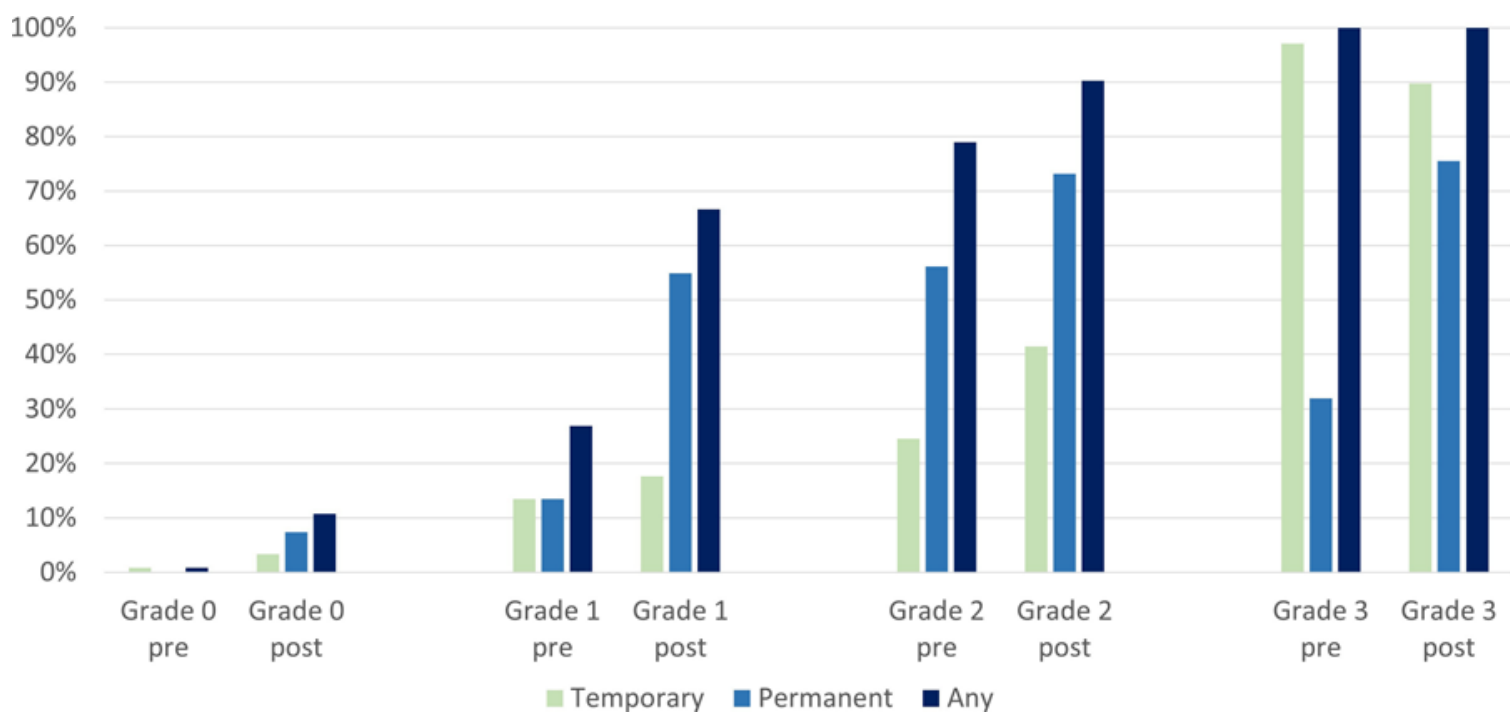

FIG. 8. Buttress use (classified as temporary, permanent, or any) stratified by CSF leak grade before and after post-protocol implementation. The pre-protocol period (pre) included 261 operations, and the period after protocol implementation (post) included 290 operations.

increased from $15 \%(22 / 143)$ to $51 \%(72 / 141)(\mathrm{p}<0.001)$. Use of any buttress (permanent or temporary) increased for grade 1 leaks from $27 \%$ to $67 \%$ ( $p<0.001)$. Use of an abdominal fat graft for grade 0 leaks increased from $21 \%(25 / 118)$ to $42 \%(62 / 149)(\mathrm{p}<0.001)$. For grade 3 leak repairs, use of pedicled flaps (nasoseptal flap or middle turbinate flap) increased from $71 \%$ to $88 \%(\mathrm{p}=0.05)$.

\section{Discussion}

\section{Summary of Experience}

In this series of 509 patients with 551 operations, the skull base repair failure rate was $1.6 \%$ overall and $3.2 \%$ for operations in which there was an intraoperative CSF leak. The bacterial meningitis rate was $1.1 \%$ overall and $2.1 \%$ for patients with an intraoperative CSF leak. The presence of any intraoperative CSF leakage (grade 1,2, or 3 ), elevated BMI, inadequate buttress placement, and postextubation vomiting or bucking were common risk factors for postoperative CSF rhinorrhea. Additionally, the presence of any intraoperative CSF leak was associated with the development of meningitis, and a postoperative repair failure was even more strongly associated with meningitis. The repair failure rate and meningitis rate trended down in the second part of the series, which was associated with an increased use of buttressing (permanent and/or temporary) across grade 1,2, and 3 leaks, a stricter antibiotic dosing protocol, and lack of lumbar CSF diversion. To our knowledge, this is the largest and most comprehensive and detailed analysis of endoscopic skull base repair to date, critically assessing failure rates by leak grade and pathology, and rates and risk factors for postoperative meningitis.

\section{CSF Leak and Meningitis Rates in Recent Publications}

The repair failure rate and postoperative meningitis rates in endoscopic skull base tumor surgery have varied over the last 15 years, but the trend has been encouragingly downward. Progress has clearly been made at many centers, especially after the advent of the pedicled nasal septal flap first introduced by Hadad et al. ${ }^{14}$ and Kassam et al..$^{20}$ over a decade ago. As shown in Table 8, overall CSF leak rates have ranged from $3 \%$ to $15.9 \%$ for mixed pathology series, with lower rates for pituitary adenomas (ranging from $0.6 \%$ to $5 \%$ ), and higher rates for craniopharyngiomas (ranging from $3.8 \%$ to $23.4 \%$ ). Similarly, meningitis rates have ranged from $0.7 \%$ to $10 \%$ for mixed pathology series, from $0 \%$ to $3.4 \%$ for pituitary adenomas, and from $1 \%$ to $8 \%$ for craniopharyngiomas. An important distinction is the leak rate for patients with an intraoperative leak versus without an intraoperative leak (grade 0 vs 1,2 , or 3 by our classification)..$^{9}$ A recent paper by Fraser et al., assessing 615 patients (treated during 1997-2012), all with intradural involvement and an intraoperative CSF leak, had a leak rate of $16.7 \%$ for all patients. However, if the entire series of 1069 patients is included (with and without intraoperative CSF leaks), the overall postoperative leak rate is $9.6 \% .^{10}$ Notably, many patients in that series were treated in the pre-nasoseptal flap era, and leak rates have decreased significantly in recent years for this group as well as others. In the current series, with the nasoseptal flap in our armamentarium, the overall postoperative CSF leak rate (all grades) was 1.6\%, and for those patients with an intraoperative leak (grade 1,2, or 3) was 3.2\%. As others have shown, we demonstrated a strong association between postoperative CSF leaks and meningitis. ${ }^{16}$

\section{Evolution of Original Approach}

In comparing our 2007 paper, which included 620 patients treated with microscopic or endoscope-assisted tumor removal over an 8-year period, to the current series, the intraoperative leak rate (grade 1,2, and 3 leaks) was modestly lower in the current series (57\% vs $52 \%$ ) but the grade 3 leak intraoperative leak rate was higher $(8.7 \%$ vs $15 \%)$. This increase in grade 3 leak repairs in the current 
TABLE 8. Summary of previously published studies on intraoperative and postoperative CSF leak, meningitis, and lumbar drain use surgery in endonasal endoscopic skull base surgery

\begin{tabular}{|c|c|c|c|c|c|c|c|c|c|}
\hline Authors \& Year & Pathology & $\begin{array}{c}\text { No. of } \\
\text { Ops }\end{array}$ & $\begin{array}{l}\text { Intraop } \\
\text { CSF } \\
\text { Leak } \\
\text { Rate }\end{array}$ & $\begin{array}{c}\text { Postop } \\
\text { Leak Rate } \\
\text { w/ Intraop } \\
\text { Leak }\end{array}$ & $\begin{array}{l}\text { Postop } \\
\text { Leak } \\
\text { Rate } \\
\text { Overall }\end{array}$ & $\begin{array}{l}\text { Meningitis } \\
\text { Rate w/ } \\
\text { Intraop } \\
\text { Leak }\end{array}$ & $\begin{array}{c}\text { Meningitis } \\
\text { Rate } \\
\text { Overall }\end{array}$ & $\begin{array}{l}\text { Nasoseptal } \\
\text { Flap Usage }\end{array}$ & $\begin{array}{c}\text { Planned } \\
\text { Intraop-Periop } \\
\text { Lumbar Drain } \\
\text { Usage }\end{array}$ \\
\hline Esposito et al., 2007 & Pituitary adenoma & 503 & $54.0 \%$ & $3.7 \%$ & $2.0 \%$ & $0 \%$ & $0.5 \%$ & $0 \%$ & NR \\
\hline Yano et al., 2009 & Pituitary adenoma & 213 & NR & NR & $4.2 \%$ & NR & NR & NR & $3.8 \%$ \\
\hline Gondim et al., 2010 & Pituitary adenoma & 251 & NR & NR & $3.2 \%$ & NR & $0.8 \%$ & NR & NR \\
\hline Berker et al., 2013 & Pituitary adenoma & $733^{*}$ & $18.4 \%$ & $8.9 \%$ & $1.6 \%$ & NR & NR & $7.4 \%$ & NR \\
\hline Halvorsen et al., 2014 & Pituitary adenoma & 238 & NR & NR & $5.0 \%$ & NR & $3.4 \%$ & NR & NR \\
\hline Paluzzi et al., 2014 & Pituitary adenoma & 555 & $29.4 \%$ & NR & $5.0 \%$ & NR & $0.9 \%$ & $42.9 \%$ & NR \\
\hline Jakimovski et al., 2014 & Pituitary adenoma & 203 & $60.6 \%$ & NR & $3.0 \%$ & $0.0 \%$ & $0.0 \%$ & NR & $21.7 \%$ \\
\hline Wang et al., 2016 & Pituitary adenoma & 1166 & NR & NR & $0.6 \%$ & NR & $1.0 \%$ & NR & $0.6 \%$ \\
\hline Magro et al., 2016 & Pituitary adenoma & 300 & $34.3 \%$ & NR & $2.7 \%$ & $7.8 \%$ & $3.3 \%$ & $1 \%$ & $1.3 \%$ \\
\hline Jang et al., 2016 & Pituitary adenoma & 331 & $13.9 \%$ & $13.0 \%$ & $1.8 \%$ & NR & $0.6 \%$ & NR & $1.5 \%$ \\
\hline Current series, 2017 & Pituitary adenoma & 362 & $50.4 \%$ & $2.7 \%$ & $1.4 \%$ & $1.1 \%$ & $0.6 \%$ & $2.2 \%$ & $0.0 \%$ \\
\hline Esposito et al., 2007 & Craniopharyngioma & 30 & $90.0 \%$ & $3.7 \%$ & $3.3 \%$ & $0 \%$ & $0 \%$ & $0 \%$ & NR \\
\hline Leng et al., 2011 & Craniopharyngioma & 26 & NR & NR & $3.8 \%$ & NR & $3.8 \%$ & $34.6 \%$ & $65.0 \%$ \\
\hline Koutourousiou et al., 2013 & Craniopharyngioma & 64 & NR & NR & $23.4 \%$ & NR & $7.8 \%$ & $73.4 \%$ & NR \\
\hline Cavallo et al., 2014 & Craniopharyngioma & 103 & NR & NR & $14.6 \%$ & NR & $1.0 \%$ & $10.7 \%$ & $18.4 \%$ \\
\hline Kshettry et al., 2016 & Craniopharyngioma & 43 & NR & NR & $20.9 \%$ & NR & $4.7 \%$ & $72.1 \%$ & NR \\
\hline Current series, 2017 & Craniopharyngioma & 25 & $92.0 \%$ & $8.7 \%$ & $8.0 \%$ & $8.7 \%$ & $8.0 \%$ & $80.0 \%$ & $4.0 \%$ \\
\hline Esposito et al., 2007 & Mixed tumor types & 668 & $57.0 \%$ & $4.0 \%$ & $2.5 \%$ & $0.8 \%$ & $0.5 \%$ & NR & NR \\
\hline Nicolai et al., 2008 & Mixed tumor types & 134 & NR & NR & $3.0 \%$ & NR & $0.7 \%$ & NR & NR \\
\hline Zanation et al., 2009 & Mixed tumor types & 70 & $100.0 \%$ & $5.7 \%$ & $5.7 \%$ & NR & NR & $100.0 \%$ & $92.9 \%$ \\
\hline Kong et al., 2011 & Mixed tumor types & 124 & $37.1 \%$ & $10.9 \%$ & $4.0 \%$ & $17.4 \%$ & $6.5 \%$ & $4.8 \%$ & $21.0 \%$ \\
\hline Kassam et al., 2011 & Mixed tumor types & 800 & NR & NR & $15.9 \%$ & NR & $1.5 \%$ & NR & $10.4 \%$ \\
\hline Chivukula et al., 2013 & Mixed tumor types & $171^{*}$ & $37.4 \%$ & NR & $8.2 \%$ & NR & $2.9 \%$ & $32.2 \%$ & NR \\
\hline Ivan et al., 2015 & $\begin{array}{l}\text { Mixed tumor types (all } \\
\text { extended approaches) }\end{array}$ & 98 & $61.2 \%$ & $16.7 \%$ & $11.0 \%$ & $13.3 \%$ & $10.0 \%$ & $86.7 \%$ & NR \\
\hline Fraser et al., 2018 & Mixed tumor types & 615 & $57.0 \%$ & $16.7 \%$ & $9.6 \%$ & NR & NR & $76 \%$ & $23.9 \%$ \\
\hline Current series, 2017 & Mixed tumor types & 551 & $52.0 \%$ & $3.2 \%$ & $1.6 \%$ & $2.1 \%$ & $1.1 \%$ & $12 \%$ & $0.2 \%$ \\
\hline
\end{tabular}

$\mathrm{NR}=$ not reported.

The case series reported on by Esposito et al. was endoscope-assisted but is included for historical comparison.

* Data were converted from "per patient" to "per operation."

series is likely related to a higher percentage of brain and skull base tumors (27\% vs $16 \%)$ and lower percentage of pituitary adenomas and Rathke's cleft cysts (73\% vs $84 \%$ ) in the current endoscopic series. In both experiences, we demonstrated a learning curve with reduction in leak rate in the later phase of the study down to an overall leak rate of $1 \%$. However, in comparing grade 3 leaks alone, the decrease was more substantial in this most recent cohort, decreasing from $9 \%$ to $2 \%$, compared with a decline from $17.9 \%$ to $6.7 \%$ in the earlier series. We would attribute this improved grade 3 leak failure rate mostly to incorporation of the nasoseptal flap ${ }^{20}$ and more liberal use of soft and permanent buttresses. Another important difference in these 3 series is the elimination of Bioglue surgical adhesive in early 2012, which we subsequently associated with a relatively high rate of delayed sinusitis in patients in whom it was used. ' Our current preference for tissue glue is Tisseel fibrin sealant, which is layered over the most superficial layer of collagen matrix simply to help hold the repair materials in place and not to actually stop or seal the CSF leak. Additionally, we discontinued use of titanium mesh in late 2011 and have subsequently made an effort to use autologous septal or vomer bone whenever possible. Autologous materials, including abdominal fat, nasoseptal bone, and native mucosa, have obvious advantages in terms of tissue compatibility and survival compared with allografts and synthetics. When sufficient bone is unavailable, we typically use a Medpor TSI implant, which can be precisely cut, has sufficient malleability, and has a handle for easy placement.

\section{Utility of Prophylactic Lumbar CSF Diversion}

In the current series, a lumbar drain was used in only 4 patients, with a higher rate of meningitis (not statistically significant). The literature remains unclear on both the benefits and risk of CSF diversion as an adjunct in repairing high-grade leaks. At some centers, it is used routinely with 
good success, predominantly for larger (grade 3) leaks, while in others, it may be associated with a higher failure rate and meningitis rate.,10,17 Two recent meta-analyses and a systematic review article failed to find benefit of perioperative lumbar drain placement in patients undergoing endoscopic skull base surgery, and one emphasized potential risk of major complications, including meningitis and ventriculitis. ${ }^{1,5,16}$ These data have also been incorporated into the Congress of Neurological Surgeons (CNS) guidelines for nonfunctional pituitary adenoma resection, wherein they concluded that there is insufficient data to recommend use of perioperative CSF diversion to prevent postoperative CSF leakage. ${ }^{25}$ Based on these 3 recent publications, the CNS guideline recommendation, and our current experience, including a possibly higher risk of meningitis, lumbar drains appear to be unwarranted for lower-grade leaks (grades 1 and 2) and may be unnecessary for grade 3 leaks if a multilayered repair that includes a pedicled flap is performed and effectively buttressed. Furthermore, use of a lumbar drain may provide a "false sense of security" to the surgical team and perhaps even make them more complacent in performing a meticulous repair. Importantly, this part of the procedure is one of the most critical, and for large tumors such as craniopharyngiomas, tuberculum sellae meningiomas, chordomas, and giant adenomas with intradural extension, great care must be taken in creating an effective skull base reconstruction. Whether our routine use of acetazolamide (500 mg every 8 hours for 48 hours) for patients with any grade 1,2, or 3 leak is beneficial is uncertain. However, given its relative safety and our low failure rate ( $1 \%$ overall and $2 \%$ for grade 3 leaks) with this regimen, we will continue administering it.

\section{Key Technical Points and Management Recommendations to Minimize Repair Failures and Meningitis}

It is apparent that the great majority of CSF leaks and cases of meningitis can be avoided. To minimize this risk and to achieve a rate lower than $1 \%$ for each of these complications, several recommendations are provided.

\section{Nasal Phase of Surgery}

During the approach, it is useful to harvest septal bone if available. Such bone should be removed in as large a piece as possible and kept in antibiotic-soaked gauze until closure so that it can be tailored for sellar, parasellar, or clival skull base repair.

\section{Sphenoid Sinus Phase of Surgery}

For grade 0,1 , and 2 leaks, one should attempt to preserve and reflect as much of the sphenoid sinus mucosa that overlays the sellar region as possible. This mucosa can typically be incised vertically and then reflected laterally away from the midline. At closure, this mucosa can then be repositioned over the sellar/parasellar repair (see Video 1 for grade 1 and 2 leak repairs). For cases in which a grade 3 leak and need for a nasoseptal flap are anticipated, removal of all sphenoid sinus mucosa is indicated to ensure that the flap adheres fully to the skull base.

\section{Bony Removal of Sella and Parasellar Skull Base}

Care should be taken to not overexpose for the given pathology, making the defect more expansive and problematic to repair. While the bony opening should adequately expose the pathology, excessive bone removal of the sellar floor or over the cavernous sinus will limit or eliminate the possibility of wedging a permanent buttress (e.g., bone or Medpor TSI) into the sellar defect. Additionally, removal of the sellar floor can increase the risk of fat graft and collagen migration away from the defect due to gravity. Similarly, the dural opening should be appropriate for the pathology, and there is little benefit in opening dura far from the pathology. Extending the dural opening high superiorly also risks creating an early anterior grade 1 or 2 leak. Resection of involved anterior or inferior sellar dura with an invasive adenoma or tuberculum meningioma is certainly reasonable, but removal of uninvolved dura leaves a larger defect to repair and likely increases the risk of a postoperative leak.

\section{Closure, Hemostasis, and Tissue Glues}

During the closure, obtaining adequate sinonasal hemostasis with hemostatic agents and warm irrigation is essential. Prior to extubation, the oropharynx and stomach should be suctioned with a nasogastric tube (placed under direct endoscopic visualization), to minimize the irritation of gastric blood, which can potentiate postoperative nausea and vomiting, and possible dislodgement of the repair construct at the skull base (throat packs are not used). Regarding nasal packing, if a solid buttress cannot be wedged into the intrasellar defect and the patient is at high risk for a postoperative leak (high BMI, thinned diaphragm, prior surgery and/or radiation), then placement of a single or bilateral Merocel sponge(s) under direct endoscopic visualization is strongly recommended (see Video 1 for grade 3 leak repair). While placement of nasal sponges may result in some patient discomfort over the 5 days they are in place, it is far preferable to having a postoperative CSF leak.

\section{Anesthesia Considerations.}

Close communication with the anesthesiologist is also essential to promote a smooth emergence from anesthesia, avoiding "bucking" on the endotracheal tube, and administering antiemetics to minimize the risk of post-extubation nausea and vomiting.

\section{Limitations of This Study}

The major limitation of this study is the somewhat arbitrary demarcation of the first and second parts of the study, which was chosen based on implementation of a stricter antibiotic protocol and an increased and more liberal use of permanent or temporary buttresses for all leak grades. As is often the case in clinical neurosurgery, we learn as we go along and modify our practice based on failures and suboptimal outcomes. In our view, a randomized trial, for example, assessing the use of soft buttresses for grade 3 leaks, would not be appropriate, and we would not want to expose our patients to the potentially increased risk of a postoperative leak or meningitis.

Another potential critique is the grading system itself. It too is somewhat arbitrary and based upon an intraoperative assessment. Some would contend that, for example, 
distinguishing between grade 1 and grade 2 leaks can be difficult and that there may be some degree of interobserver variability. While these are valid points, given that we published on this methodology a decade ago, that we have been consistent in its subsequent application, and that this grading system has been incorporated and cited in subsequent studies, ${ }^{31,35}$ we believe it still has validity and utility in trying to describe and treat skull base defects and associated CSF leaks.

\section{Conclusions}

Effective skull base repair with avoidance of postoperative CSF leaks and meningitis continues to be a challenge in endonasal endoscopic surgery. This study highlights the outcomes and evolution of repair technique in a series of over 500 consecutive patients in a 7 -year period, providing a failure analysis of this graded repair protocol. With consistent technique and meticulous attention to both intraoperative and perioperative management, achieving a rate near $0 \%$ for skull base repair failure and meningitis should be the ultimate goal.

\section{References}

1. Ahmed OH, Marcus S, Tauber JR, Wang B, Fang Y, Lebowitz RA: Efficacy of perioperative lumbar drainage following endonasal endoscopic cerebrospinal fluid leak repair. Otolaryngol Head Neck Surg 156:52-60, 2017

2. Berker M, Aghayev K, Yücel T, Hazer DB, Onerci M: Management of cerebrospinal fluid leak during endoscopic pituitary surgery. Auris Nasus Larynx 40:373-378, 2013

3. Cavallo LM, Frank G, Cappabianca P, Solari D, Mazzatenta D, Villa A, et al: The endoscopic endonasal approach for the management of craniopharyngiomas: a series of 103 patients. J Neurosurg 121:100-113, 2014

4. Chivukula S, Koutourousiou M, Snyderman CH, FernandezMiranda JC, Gardner PA, Tyler-Kabara EC: Endoscopic endonasal skull base surgery in the pediatric population. $\mathbf{J}$ Neurosurg Pediatr 11:227-241, 2013

5. D'Anza B, Tien D, Stokken JK, Recinos PF, Woodard TR, Sindwani R: Role of lumbar drains in contemporary endonasal skull base surgery: meta-analysis and systematic review. Am J Rhinol Allergy 30:430-435, 2016

6. de Divitiis E, Laws ER, Giani U, Iuliano SL, de Divitiis O, Apuzzo ML: The current status of endoscopy in transsphenoidal surgery: an international survey. World Neurosurg 83:447-454, 2015

7. Dusick JR, Mattozo CA, Esposito F, Kelly DF: BioGlue for prevention of postoperative cerebrospinal fluid leaks in transsphenoidal surgery: a case series. Surg Neurol 66:371-376, 2006

8. Esposito F, Becker D, Villablanca J, Kelly D: Endonasal transsphenoidal transclival removal of prepontine epidermoid tumors. Neurosurgery 56 (2 Suppl):E443, 2005

9. Esposito F, Dusick JR, Fatemi N, Kelly DF: Graded repair of cranial base defects and cerebrospinal fluid leaks in transsphenoidal surgery. Neurosurgery 60 (4 Suppl 2):295-304, 2007

10. Fraser S, Gardner PA, Koutourousiou M, Kubik M, Fernandez-Miranda JC, Snyderman $\mathrm{CH}$, et al: Risk factors associated with postoperative cerebrospinal fluid leak after endoscopic endonasal skull base surgery. J Neurosurg 128:1066-1071, 2018

11. Garcia-Navarro V, Anand VK, Schwartz TH: Gasket seal closure for extended endonasal endoscopic skull base surgery: efficacy in a large case series. World Neurosurg 80:563-568, 2013
12. Gondim JA, Schops M, de Almeida JPC, de Albuquerque LAF, Gomes E, Ferraz T, et al: Endoscopic endonasal transsphenoidal surgery: surgical results of 228 pituitary adenomas treated in a pituitary center. Pituitary 13:68-77, 2010

13. Griffiths CF, Cutler AR, Duong HT, Bardo G, Karimi K, Barkhoudarian G, et al: Avoidance of postoperative epistaxis and anosmia in endonasal endoscopic skull base surgery: a technical note. Acta Neurochir (Wien) 156:1393-1401, 2014

14. Hadad G, Bassagasteguy L, Carrau RL, Mataza JC, Kassam A, Snyderman $\mathrm{CH}$, et al: A novel reconstructive technique after endoscopic expanded endonasal approaches: vascular pedicle nasoseptal flap. Laryngoscope 116:1882-1886, 2006

15. Halvorsen H, Ramm-Pettersen J, Josefsen R, Rønning P, Reinlie S, Meling T, et al: Surgical complications after transsphenoidal microscopic and endoscopic surgery for pituitary adenoma: a consecutive series of 506 procedures. Acta Neurochir (Wien) 156:441-449, 2014

16. Ivan M, Iorgulescu J, El-Sayed I, McDermott M, Parsa A, Pletcher S, et al: Risk factors for postoperative cerebrospinal fluid leak and meningitis after expanded endoscopic endonasal surgery. J Clin Neurosci 22:48-54, 2015

17. Jakimovski D, Bonci G, Attia M, Shao H, Hofstetter C, Tsiouris AJ, et al: Incidence and significance of intraoperative cerebrospinal fluid leak in endoscopic pituitary surgery using intrathecal fluorescein. World Neurosurg 82:e513e523, 2014

18. Jang JH, Kim KH, Lee YM, Kim JS, Kim YZ: Surgical results of pure endoscopic endonasal transsphenoidal surgery for 331 pituitary adenomas: a 15 -year experience from a single institution. World Neurosurg 96:545-555, 2016

19. Kassam AB, Prevedello DM, Carrau RL, Snyderman CH, Thomas A, Gardner P, et al: Endoscopic endonasal skull base surgery: analysis of complications in the authors' initial 800 patients. J Neurosurg 114:1544-1568, 2011

20. Kassam AB, Thomas A, Carrau RL, Snyderman CH, Vescan A, Prevedello D, et al: Endoscopic reconstruction of the cranial base using a pedicled nasoseptal flap. Neurosurgery 63 (1 Suppl 1):ONS44-ONS53, 2008

21. Kelly DF, Griffiths CF, Takasumi Y, Rhee J, Barkhoudarian G, Krauss HR: Role of endoscopic skull base and keyhole surgery for pituitary and parasellar tumors impacting vision. J Neuroophthalmol 35:335-341, 2015

22. Kong DS, Kim HY, Kim SH, Min JY, Nam DH, Park K, et al: Challenging reconstructive techniques for skull base defect following endoscopic endonasal approaches. Acta Neurochir 153:807-813, 2011

23. Koutourousiou M, Gardner PA, Fernandez-Miranda JC, Tyler-Kabara EC, Wang EW, Snyderman CH: Endoscopic endonasal surgery for craniopharyngiomas: surgical outcome in 64 patients. J Neurosurg 119:1194-1207, 2013

24. Kshettry VR, Do H, Elshazly K, Farrell CJ, Nyquist G, Rosen $\mathrm{M}$, et al: The learning curve in endoscopic endonasal resection of craniopharyngiomas. Neurosurg Focus 41(6):E9, 2016

25. Kuo JS, Barkhoudarian G, Farrell CJ, Bodach ME, Tumialan LM, Oyesiku NM, et al: Congress of Neurological Surgeons systematic review and evidence-based guideline on surgical techniques and technologies for the management of patients with nonfunctioning pituitary adenomas. Neurosurgery 79:E536-E538, 2016

26. Leng LZ, Greenfield JP, Souweidane MM, Anand VK, Schwartz TH: Endoscopic, endonasal resection of craniopharyngiomas: analysis of outcome including extent of resection, cerebrospinal fluid leak, return to preoperative productivity, and body mass index. Neurosurgery 70:110-124, 2011

27. Lobo B, Zhang X, Barkhoudarian G, Griffiths CF, Kelly DF: Endonasal endoscopic management of parasellar and cavernous sinus meningiomas. Neurosurg Clin N Am 26:389-401, 2015 
28. Magro E, Graillon T, Lassave J, Castinetti F, Boissonneau S, Tabouret E, et al: Complications related to the endoscopic endonasal transsphenoidal approach for nonfunctioning pituitary macroadenomas in 300 consecutive patients. World Neurosurg 89:442-453, 2016

29. Nicolai $P$, Battaglia $P$, Bignami $M$, Bolzoni Villaret $A$, Delù G, Khrais T, et al: Endoscopic surgery for malignant tumors of the sinonasal tract and adjacent skull base: a 10-year experience. Am J Rhinol 22:308-316, 2008

30. Paluzzi A, Fernandez-Miranda JC, Stefko ST, Challinor S, Snyderman CH, Gardner PA: Endoscopic endonasal approach for pituitary adenomas: a series of 555 patients. Pituitary 17:307-319, 2014

31. Park JH, Choi JH, Kim YI, Kim SW, Hong YK: Modified graded repair of cerebrospinal fluid leaks in endoscopic endonasal transsphenoidal surgery. J Korean Neurosurg Soc $\mathbf{5 8 : 3 6 - 4 2 , 2 0 1 5}$

32. Wang AJ, Zaidi HA, Laws ED Jr: History of endonasal skull base surgery. J Neurosurg Sci 60:441-453, 2016

33. Yano S, Kawano T, Kudo M, Makino K, Nakamura H, Kai Y, Morioka M, Kuratsu JI: Endoscopic endonasal transsphenoidal approach through the bilateral nostrils for pituitary adenomas. Neurol Med Chir (Tokyo) 49:1-7, 2009

34. Zanation AM, Carrau RL, Snyderman CH, Germanwala AV, Gardner PA, Prevedello DM, et al: Nasoseptal flap reconstruction of high flow intraoperative cerebral spinal fluid leaks during endoscopic skull base surgery. Am J Rhinol Allergy 23:518-521, 2009

35. Zhang M, Singh H, Almodovar-Mercado GJ, Anand VK, Schwartz TH: Required reading: the most impactful articles in endoscopic endonasal skull base surgery. World Neurosurg 92:499-512, 512.e1-512.e2, 2016

\section{Disclosures}

Dr. Carrau reports a consultant relationshp with Medtronic Corp. Dr. Barkhoudarian reports a consultant relationship with VTI. Dr. Kelly reports receipt of royalties from Mizuho, Inc.

\section{Author Contributions}

Conception and design: Kelly, Conger, Zhao, Barkhoudarian. Acquisition of data: Kelly, Conger, Zhao, Wang, Eisenberg, Griffiths, Barkhoudarian. Analysis and interpretation of data: Kelly, Conger, Zhao, Eisenberg, Griffiths, Esposito, Carrau, Barkhoudarian. Drafting the article: Kelly, Conger, Zhao, Wang, Griffiths, Barkhoudarian. Critically revising the article: Kelly, Conger, Griffiths, Esposito, Carrau, Barkhoudarian. Reviewed submitted version of manuscript: all authors. Approved the final version of the manuscript on behalf of all authors: Kelly. Statistical analysis: Barkhoudarian. Administrative/technical/material support: Kelly. Study supervision: Kelly.

\section{Supplemental Information Videos}

Video 1. https://vimeo.com/248162565.

\section{Previous Presentations}

This abstract was presented at the 2018 North American SkullBase Society Annual Meeting, Coronado, CA, in Februrary 16-18, 2018.

\section{Correspondence}

Daniel F. Kelly: Pacific Neuroscience Institute \& John Wayne Cancer Institute, Providence Saint John's Health Center, Santa Monica, CA. kellyd@jwci.org. 